\title{
Research on the Counselors publicity strategy based on Internet+
}

\author{
Jinging Gao \\ Xi'an FANYI University, Shaanxi, Xi'an 710105, China \\ E-mail: 280204295@qq.com
}

\begin{abstract}
With the rapid development of mobile communication technology and the increasing popularization of smart mobile devices, the mobile Internet era has come, leading to great changes in contemporary university students' life and learning.objective: Basing on Internet+ perspective, studies on counselors publicity strategy, and provides policy advice to its smooth and effective conduct counselor advocacy work. Method: This paper studies new propagation characteristics of the New College Counselors from the perspective of communication; Through research model, analyze the opportunities and challenges of counselors publicity based on Internet+ ; And we chose Micro letter as the representative, and analyze innovative practice of counselor publicity strategy of Internet+; Finally analyze problems and solutions of counselors promotional strategies based on Internet+. Results: The successful application of micro letter on counselor publicity work. Conclusion: Internet+ counselors publicity strategy can improve the efficiency of its counselors, and provides policy advice to its smooth and effective conduct counselor advocacy work.
\end{abstract}

Keywords-Internet+; Counselors advocacy work; Communication Study; Micro-letter; Strategy research

\section{INTRODUCTION}

With the rapid development of mobile communication technology and the increasing popularization of smart mobile devices, the mobile Internet era has come,leading to great changes in contemporary university students' life and learning. The changes are both challenges and opportunities for university counselors. How to use mobile Internet to change the way of work,expand the time and space of work,and improve the efficiency of work,are issues every university counselor should consider. However, through research found that counselors propaganda work's study method based on internet+ has little domestic innovation. Previous studying on the traditional Internet environment is outdated, unable to give specific guidance and help now. So, Research on the Counselors publicity strategy based on Internet+ has extremely important practical value.

\section{COLLEGE COUNSELORS PROPAGANDA WORK'S NEW PROPAGATION CHARACTERISTICS IN THE NEW PERIOD}

\section{A. Counselors publicity related concepts}

Publicity universities[1] mainly refers to the university management team to its subject, its work in order to carry out targeted university students, involving campus order management, student ideological guidance, image-building in all aspects of universities, the concept of socialism with Chinese characteristics system boot and so on.

Counselors propaganda Universities[2] is a specific dissemination activities. As a specific propagation behavior, college counselors advocacy and dissemination of other human activity, it has its own Propagation purposes. The purpose of human activity is to spread hope changes accordingly, whether the dissemination of information or receive information, every person involved in the activities, are intentional, purposeful and have consciousness of motivation. In this sense, the Counselors publicity Universities also have their own Propagation purposes. In short, in order to firmly grasp propaganda guidance, improve the ideological and political quality of college students, so that students can achieve "builders of socialism with Chinese characteristics and successors" standard.

Colleges in the New propagation environment has undergone tremendous changes. Internet, mobile phones, microblogging and other new media of mass resistance, occult, sudden, causes a crisis of public universities and emergencies frequently, and has brought great harm to the security and stability of colleges and universities. As the reality of the spread of the phenomenon,new era college counselors publicity strategy, needs for new propagation characteristics of the propagation occurred during analysis.

\section{B. Communicators}

Communicators information communication[3] in the first link of the chain, is the sponsor of dissemination activities, as well as dissemination of the contents of the issuer. Therefore, Communicators not only determines the existence and development of communication activities, and determine the quality and quantity, flow rate and the flow of information content, but also determines the role and impact on human society.

New Era College Counselors[4] its work in this particular communication activities, college counselors as outreach activities communicators, self-image building in the presence of bias, which greatly disturbed the benign guidance of the dissemination of results. First, the rights and status of low-impact Communicators spread effect. As higher education management institutions, emphasis on teaching and research, so that with the ideological and political work in teaching and research work subordination. This led directly to the teaching and scientific research and information transfer is affected by the environment of the master's level, in contrast, ideological and political education Communicators - lower college counselors as Communicators authority. Second, seniority and prestige Communicators lead to reduced lower sense of trust 
communicators. College Counselors low age, low education is a common problem in all colleges and universities, which is conducive to student groups close to the college counselors, students carry out the work, but work as a propaganda communicators universities, college or graduate school that is engaged in Universities youth counselors, the relative lack of experience, no rich life experiences, for the audience is college students, the sense of trust in the communicator will be greatly reduced. Third, the lack of expertise Communicators lead to the spread effect reduced.

Currently, Chinese universities' counselors widespread problem of low degree of specialization. Some colleges and universities have a system of theoretical knowledge, with the ideological education teaching and research capability of staff, and have not engage in a specific job counselor. Counselors engaged in the work of staff, graduates from many professional institutions, lack of ideological education work of professional knowledge and theoretical basis. Such realities, results in the former work easily formed dogma, boring stereotype to the audience. The latter work is easy to cause the audience simple, objective means rough impression, which is not conducive to effectively guide the dissemination of results.

\section{Propagation content}

Communication content is the core and fundamental purpose of the entire communication activities. Counselors in the New Collegiate Propaganda Work of this particular communication activities, the Communication content included political education, ideological and moral education, law and discipline education, psychological education in five aspects.

College Counselors publicity work, we must ensure the correctness and Propagation authoritative source, ensure Propagation content to produce benefits for the purpose, ensure the Communication content of concentration. In particular, that efforts to promote the theoretical system of socialism with Chinese characteristics, efforts to promote scientific concept of development, adhere to scientific development to enhance the consciousness and firmness.

In the college Counselors propaganda work, propagation content is a problem that can not meet the needs of the audience. The main reason is: on the one hand due to the advocacy work of College Counselors in the mass Communication content is not as content as a starting point to the economic benefits, but includes motivation and purpose are established so that students want to understand, agree to accept their views, for the audience, the lack of attractive Propagation content. On the other hand, the high degree of integration of information today, Counselors advocacy work in Universities tend to be more emphasis on content Propagation propaganda and political norms, light-sided emphasis on individual needs and social values, education and the one-sided emphasis on light reality over education, and the students' practical learning living far from easy to arouse students' identity and emotional resonance, resulting in the formation of gully between Communication content and communication needs, not only from a good dissemination of results, and even play a counter-excitation psychological reactance.

\section{Media}

Media[5], namely transfer of information tools and instruments, such as telephones, computers and networks, newspapers, radio, television and other media and communication technology-related, level of development as a technical means of how to determine the media of social communication speed, range and efficiency.

New Era intermediary for the innovation brings great changes in the new era of social communication environment. With digital technology, network technology and communication technology advances, the Internet, mobile phones and new forms of media such as mobile TV, building TV, electronic magazines and other rapid development, making diversified media situation, people receive information more diverse channels, public opinion to guide more complicated.

Counselors publicity Universities dissemination[6] of ideas current relatively old, well-established system architecture from the campus media, such as magazine newspaper, campus radio and other traditional media, or the campus network and other official media communication is still the mainstream platform. Single conservative media does not meet the Propagation the audience, that the information needs of the student population for text, images, voice, video, animation and other media, it is difficult to make educational content from plane to three-dimensional, interactive lack of communication, which greatly affect dissemination of results.

\section{E. Mobile Internet give opportunities and challenges to the Counselors work}

By the author of 500 students in a school questionnaires findings we found that have mobile phones, tablet PCs and other mobile Internet devices accounted for $98 \%$. Daily time online these devices over one hour of $84 \%$. More than three hours of $40 \%$. More than $85 \%$ of the students will refresh microblogging micro-letters and sociability applications every day.

Students[7] widely used the case of the mobile Internet and counselors who actually work eventful miscellaneous and other features, it is easy to see in the actual work Counselors mobile Internet use new tools of necessity and superiority. This outreaching Counselors space, improving efficiency, working new methods and changing work ethic are undoubtedly a rare opportunity. Everything has two sides, opportunities and challenges. Really work is to make good use of mobile Internet and other new media, with a clever too easy. It puts forward higher requirements for counselors personal qualities and abilities, time and effort. Further increase the difficulty of the work. More importantly, the initiative to change the past, requires Counselors familiar work patterns and methods of work. This is no small in terms of its challenge.

\section{RESEARCH ON THE COUNSELORS PUBLICITY STRATEGY BASED ON INTERNET +---MICRO LETTER AS THE REPRESENTATIVE}

Students widely used the case of the mobile Internet and counselors who actually work eventful miscellaneous and other features, it is easy to see in the actual work Counselors mobile Internet use new tools of necessity and superiority. This outreaching Counselors space, improving 
efficiency, working new methods and changing work ethic are undoubtedly a rare opportunity. Everything has two sides, opportunities and challenges. Really work is to make good use of mobile Internet and other new media, with a clever too easy. It puts forward higher requirements for counselors personal qualities and abilities, time and effort. Further increase the difficulty of the work. More importantly, the initiative to change the past, requires Counselors familiar work patterns and methods of work. This is no small in terms of its challenge.

\section{A. micro letter overview}

micro letter[8] is a new voice tool that meets real-time communication launched by Tencent in early 2011 . Users can quickly send voice, video, image and text through mobile phones, tablet PCs, web pages. Further, shake, searching for a number, people in the vicinity, sweep the two-dimensional code the way users can add friends and concerned public platform, and can be a wonderful life, moving to micro letter instantly timely sharing circle of friends. It has the characteristics of cross-platform, low cost and communication diversity. So, once launched on the favorite by the majority of college students in the high penetration rate among students. The view of the contents of miscellaneous counselors, job requirements and target high number of features. The use of micro letter innovation work in Counselors becomes feasible and very necessary.

Micro letter as a tool plays the biggest role in the actual work. We must first fully understand the functions and features of each micro letter.Second, it must be innovative and concrete work combined. The final step is to vigorously promote the students to improve attention related to micro letter so as to actually use them and play a role.

\section{B. Specific Strategies}

The introduction of new media platforms Counselors work with universities to promote its inevitability, it is Propagation environment to the new requirements of contemporary university management proposed a new trend. Currently, new media exhibited unprecedented speed, high-capacity, interactive, high-quality and other advantages, far more than the traditional print media and electronic media.

Research on the Counselors publicity strategy abide by the following principles, which is shown as Fig .1[9].And the specific Strategies based on Internet+ is as follows:

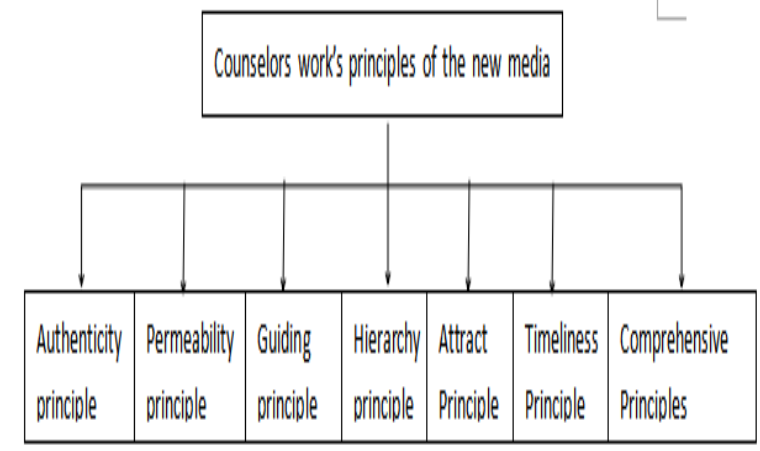

Figure 1. The principles of research on the Counselors publicity strategy

Build schools and counselors micro letter public number, to play its "radio station" function. micro letter public number can through user groups and regional control on the background, can achieve and communicate with the full range, interact and precise message push the text, images, voice of specific groups .

The use of micro-channel this powerful feature, establish schools and counselors personal name public micro-channel number, and its development into a "radio station" and "propaganda station." Firstly, the public micro-channel number can notice a variety of activities, time and place of the meeting, publish a variety of announcements and notifications associated with students, so that students can learn anytime and anywhere the latest college dynamic. Compared to traditional Web information dissemination, public micro-channel number more timely. Secondly, a variety of tips and holiday greetings, such as timely bedroom fire alarm prompt, holiday travel safety, cooling warm tips so narrow the distance between students and instructors, so the feelings between students and teachers is more intimate, getting along more harmonious. Finally, it became our micro-channel platform to carry out ideological and political education of propaganda station. Combined nowadays hotspots, implants correct, positive values and world view, mastered the right to speak among students. In the micro-channel environment, sometimes some negative propagation speed and breadth of information far beyond the positive information, while college students lack social experience and the ability to identify, easily influenced. This requires us to publish timely counselor correct perception and understanding on hot issues, establish the correct value orientation among students, to guide students on the proper awareness.

Establish grade, professional and classes micro-group, to make memories more efficient and flexible

If the micro letter public number compared to the "radio station", then the micro-group is the "conference room", is the place to brainstorm everyone from space and time constraints. Under the traditional model, such as Counselors need to give a class or a student meeting firstly that should have to consider the time and place of the meeting. The micro-group meeting, it may less restricted, more flexible. In addition, since the face to avoid embarrassment, students may speak less worry, more straight from the heart, they are more willing to participate in interactive. Also, you can organize a hot topic for the convening of micro-group discussion topic. Not only help students to show themselves, and it helps establish the correct guidance of public opinion among the students.

\section{C. problems and countermeasures}

Through micro letter Counselors work in practice in the use of innovative mobile Internet proves that it plays a significant role in improving the efficiency and changing Counselors working models[10]. Let us fully appreciate the mobile Internet to Counselors work opportunities, but there is also some big challenge.

The main challenges are:

First, counselors work situation is characterized by more people and much more eventful, so it is difficult to extract enough time and energy to take care of these network public platform. So that students in a networked environment viscous enough, is not conducive to give full play to the role of new tools; 
Second, schools, colleges and other higher's support are not enough publicity, authoritative micro letter public platform often questioned and injuries;

Third, students using micro letter has a certain risk exists.

Main countermeasures:

First, schools should strengthen this emphasis and support. First, we should actively promote and guide the instructor to use the new media.

Second, increase investment counselors work and research. Again, strictly control the number of students for each counselor is responsible for avoiding counselors overburdened; Second, the counselors themselves to actively change their ideas, take the initiative to change, to learn advanced technology and culture. On the one hand to improve their ability to use network information and knowledge structure, bold and innovative mobile networking tools applied to specific work. On the other hand strengthen ideological and political learning, to maintain the level of theory and political education in order to become a platform for the development of the mobile network and a position of Political Education.

Third, integration of school mobile network resources to create a brand, a reputation of a network of public internet. This will not only conducive to the various communities, the administrator agencies learn from each other, but also to avoid information overload or repeated, resulting in information chaos.

Fourth, to mobilize the enthusiasm of the students, to carry out various forms, content-rich online theme activities, occupation the network ideological and political education.

\section{CONCLUSIONS}

This paper studys new propagation characteristics of the New College Counselors from the perspective of communication; Through research model, analyze the opportunities and challenges of counselors publicity based on Internet + ; And we chose Micro letter as the [11] representative, and analyze innovative practice of counselor publicity strategy of Internet + ; Finally analyze problems and solutions of counselors promotional strategies based on Internet + . The successful application of micro letter on counselor publicity work. Internet + counselors publicity strategy can improve the efficiency of its counselors, and provides policy advice to its smooth and effective conduct counselor advocacy work.

\section{ACKNOWLEDGMENTS}

This work is supported by the Social Science Foundation of Shaanxi Province(2015N023).

\section{REFERENCES}

[1] Sabir Ghauri.Analysis of uwb coexistence with $2 \mathrm{G} / 3 \mathrm{G} / 4 \mathrm{G}$ wireless communication systems[Z].a Senior Lecturer in the Department of Engineering,Design and Mathematics at Faculty of Environment and Technology at University of the West of England,Bristol,2012.

[2] X.Z.Wu. Analysis of the role of micro-blog in college counselors work. Chinese market,2012,(14),pp:120.

[3] L.S.Liu, M.W.Sun, Z.H.Huang. Information Literacy Network Environment Training Strategy of College Counselors extremely. Heilongjiang Higher Education Research, 2011 (7), pp: 91.

[4] C.F.Gao. The thinking of counselors promoting study atmosphere under the new media age. Education and Vocation, 2014,pp:42-43.

[5] Y.Wan. The development and innovation of College Counselors ideological education in the new media environment. Education and Vocation, 2012,pp: 65-68.

[6] X.Liu. Thoughts of College Counselors under the new media environment. Youth and society, 2014,pp:201-201.

[7] J.Zhao. Principles and boundaries under the new media environment of student work. College Counselors, 2012, pp: 15-19.

[8] Y.Y.Zhu. Strategies of mobile media to promote employment guidance Universities. Journal of Huaihua University, 2013, pp: 119-120.

[9] S.Liu. Mobile Media Situation and Countermeasures in Ideological and Political Education in the background under 3G. Ideological and Political Education, 2012, pp: 187.

[10] Q.Tang. Analysis of new media capabilities campus in ideological and political education. School Party and ideological education, 2012 . 